\title{
Artes Visuais no ensino fundamental na atualidade ${ }^{1}$
}

\author{
Teresinha Sueli Franz ${ }^{2}$
}

\begin{abstract}
RESUMO
Este artigo trata de fazer uma reflexão sobre mudanças, problemas e novas perspectivas no ensino de Artes Visuais no ensino fundamental na atualidade. O texto se fundamenta em uma pesquisa sobre a Educação para a compreensão crítica da arte no ensino fundamental que está em andamento no CEART desde 2004. Seguimos nesta pesquisa a perspectiva metodológica qualitativa interpretativa crítica.Para o estudo empírico foram realizadas 16 entrevistas com professores de Artes Visuais em escolas de ensino fundamental de Florianópolis. O presente texto é fruto de parte da interpretação destes dados á luz de teóricos críticos da educação e da arte.
\end{abstract}

PALAVRAS-CHAVE: Artes visuais. Ensino fundamental. Crítica. Atualidade.

Este artigo trata de fazer uma breve reflexão sobre as mudanças no ensino fundamental hoje. Estas mudanças são de diferentes âmbitos: na legislação escolar, nas metodologias e principalmente nos fundamentos do ensino em Artes Visuais na atualidade. Esta reflexão pretende apontar novos objetivos e funções desta disciplina curricular no ensino fundamental, pensando também nos problemas que surgem destas novas questões.

A LDBEN no 9.394, promulgada em 20/12/1996, no seu art. 26, § 2을 afirma: "o ensino de arte constituirá componente curricular obrigatório, nos diversos níveis da educação básica, de forma a promover o desenvolvimento cultural dos alunos". Revogada a legislação anterior, a denominação "ensino de Arte" é adotada no lugar de "Educação Artística", conforme vinha sendo chamada esta disciplina escolar desde a LDB 5.691/71. O ensino fundamental que previa inicialmente a duração mínima de oito anos, considerado obrigatório e gratuito, na escola pública, foi prolongado para nove anos, uma vez que a Lei Federal ํo 11.114, de 05/2005,

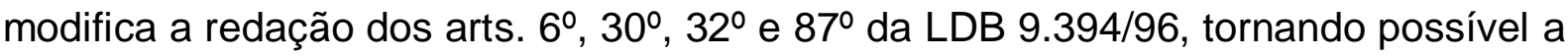
matrícula das crianças a partir dos seis anos de idade neste nível de ensino.

\footnotetext{
${ }^{1}$ Esta pesquisa teve início em agosto de 2004. No primeiro ano contou com a colaboração de um bolsista PROBIC - UDESC, o acadêmico Gustavo Dias. Naquele ano foram entrevistados nove professores de Arte de escolas de ensino fundamental em Florianópolis. No segundo ano, com nova bolsista PROBIC, desta vez a acadêmica Lila Kugler, foram entrevistados sete professores. Como pesquisa complementar outros dados foram levantados na Secretaria de Estado da Educação. Os dados estão sendo estudados e interpretados.

${ }^{2}$ Doutora em Belas Artes /Universidade de Barcelona/Espanha. Docente do Centro de Artes - UDESC Licenciatura e mestrado em Artes Visuais, Florianópolis, Santa Catarina. E-mail: terefranz@udesc.br

DAPesquisa, Florianópolis, v.2, n.4, p. 303-310, 2007.
} 
Depreende-se deste documento que o ensino fundamental passará a ter cinco anos iniciais (de seis a dez anos de idade) e quatro anos finais (de 11 a 14 anos de idade). Esta questão, no entanto, se torna obrigatória a partir da Lei oㅡ 11.274, de 06/02/2006, que instituiu a obrigatoriedade do ensino fundamental de nove anos, com matrícula aos seis anos de idade, estabelecendo prazo de cinco anos para que todos os sistemas se adaptem a esta mudança. Nesse prazo, devem ser tomadas providências, como a adaptação da estrutura física das escolas, a construção de salas de aula e a formação continuada de professores e gestores de educação. No entanto esta ampliação não está contemplada nos Parâmetros Curriculares Nacionais (PCNs) para o Ensino Fundamental, elaborados pelo Ministério da Educação (MEC). Está nas escolas desde 1997 (1aa a $4^{\text {a }}$ séries) e desde final de 1998 um volume para as $5^{\underline{a}}$ a $8^{\underline{a}}$ séries deste nível de ensino. As opiniões sobre os PCNs são diversas, em todo o caso, eles apontam para melhorias no ensino da Arte. Propõe quatro modalidades artísticas para todo o ensino fundamental: Artes Visuais (não mais apenas voltado para as Artes Plásticas, mas também para as demandas da cultura visual em geral: publicidade, cinema, Televisão, Histórias em Quadrinhos, fotografia, artes gráficas, produções com novas tecnologias,...); Música; Teatro e Dança. Esta mudança traz novas demandas em relação à formação de professores nas diversas linguagens citadas

Se esta formação já era precária na década de setenta, quando a arte foi instituída na escola como disciplina nas quatro últimas séries do então chamado $1^{\circ}$ grau (hoje ensino fundamental), onde a docência em Arte se baseava em desenvolver meras atividades artísticas, hoje, quando o ensino de Arte se direciona para a valorização dos conhecimentos específicos de cada linguagem, aumenta a exigência da presença do professor especialista em cada uma dessas linguagens citadas nos PCNs - Arte.

\section{Mudanças nos fundamentos do ensino de Artes Visuais}

Para compreender as mudanças que repercutem nas concepções pedagógicas contemporâneas e que fundamentam o Ensino de Artes Visuais na atualidade, podemos encontrar explicações na Teoria Crítica, a qual segundo Cary (1998), se refere ao papel histórico da escola e da educação, como veículo para satisfazer as necessidades de força de trabalho do complexo industrial, onde a

DAPesquisa, Florianópolis, v.2, n.4, p. 303-310, 2007. 
escola era vista como um instrumento de dominação. A partir das décadas de 50 e 60 do século XX, quando exigências tecnológicas e científicas motivaram um dramático aprofundamento das ciências e da matemática, "relegando as artes à margem dos currículos e da sociedade" (CARY, 1998, p. 40). No Brasil estes problemas tem raízes que remontam às influências liberais e positivistas do século XX, chegando ao tecnicismo, até a década de 70, como resquícios também da influência direta da guerra fria, entre outros fatores sociais (Proposta Curricular de Santa Catarina, 1998, p.192). Ao lado das tendências pedagógicas Tradicional, Escolanovista e Tecnicista, repercute no Brasil entre 1961-1964, o trabalho desenvolvido por Paulo Freire. Como explicado a seguir:

Voltado para o diálogo educador-educando e visando a consciência crítica, influencia principalmente movimentos populares e a educação não-formal. Retomado a partir de 1971, é considerado nos dias de hoje como uma 'Pedagogia Libertadora', em uma perspectiva de consciência crítica da sociedade (FERRAZ e FUZARI, 1993, p.33).

Inspirados nos ideais de Paulo Freire, aos poucos, alguns arte/educadores passam a rever suas práticas, apostando no papel da escola e da educação como agentes de transformação sociocultural. Nesta perspectiva, o professor começa a rever seu papel de mero transmissor ou facilitador para o de mediador. O ensino da arte passa ser concebido como área de conhecimento, onde, segundo Ana Mae Barbosa (1991, p.17), começamos a entender "o conceito de arteeducação como epistemologia da arte e/ou arte-educação como intermediário entre arte e público", de onde nasce também a Proposta Triangular no ensino da arte, hoje revista e compreendida como uma maneira de valorizar o fazer artístico consciente e informado, o estudo da arte erudita e popular, assim como a ampla contextualização dela.

Conscientes de seu papel na sociedade, arte/educadores pósmodernos são participantes da Pedagogia Crítica, e engajados na produção artística contemporânea, o que implica reconhecer, explorar e conciliar-se com o PósModernismo como um paradigma cultural e como um movimento estilístico (CARY, 1998). As pedagogias críticas adotam a arte de acordo com a perspectiva multicultural. Este enfoque consiste em algo além do que apenas incluir unidades e lições sobre outras culturas no currículo escolar, implica em centrar nosso interesse DAPesquisa, Florianópolis, v.2, n.4, p. 303-310, 2007. 
nos grandes temas e funções da arte, que são interculturais e transculturais. Implica também em não deixar passar a oportunidade de incluir exemplos de culturas locais e de arte, relacionados com temas mais concretos e próximos da vida dos estudantes (CHALMERS, 2003, p. 140). Na perspectiva da educação para uma compreensão crítica da arte, a obra de arte é compreendida dentro de um sistema geral de formas simbólicas a que chamamos cultura, como explica Geertz (1997), onde uma teoria da arte é ao mesmo tempo uma teoria da cultura e não um empreendimento autônomo. Estas questões levam ao ensino de Artes Visuais na perspectiva das abordagens socioculturais, o que repercute também nos conceitos de arte e nos objetivo de Artes Visuais na atualidade, como vemos no esquema a seguir.

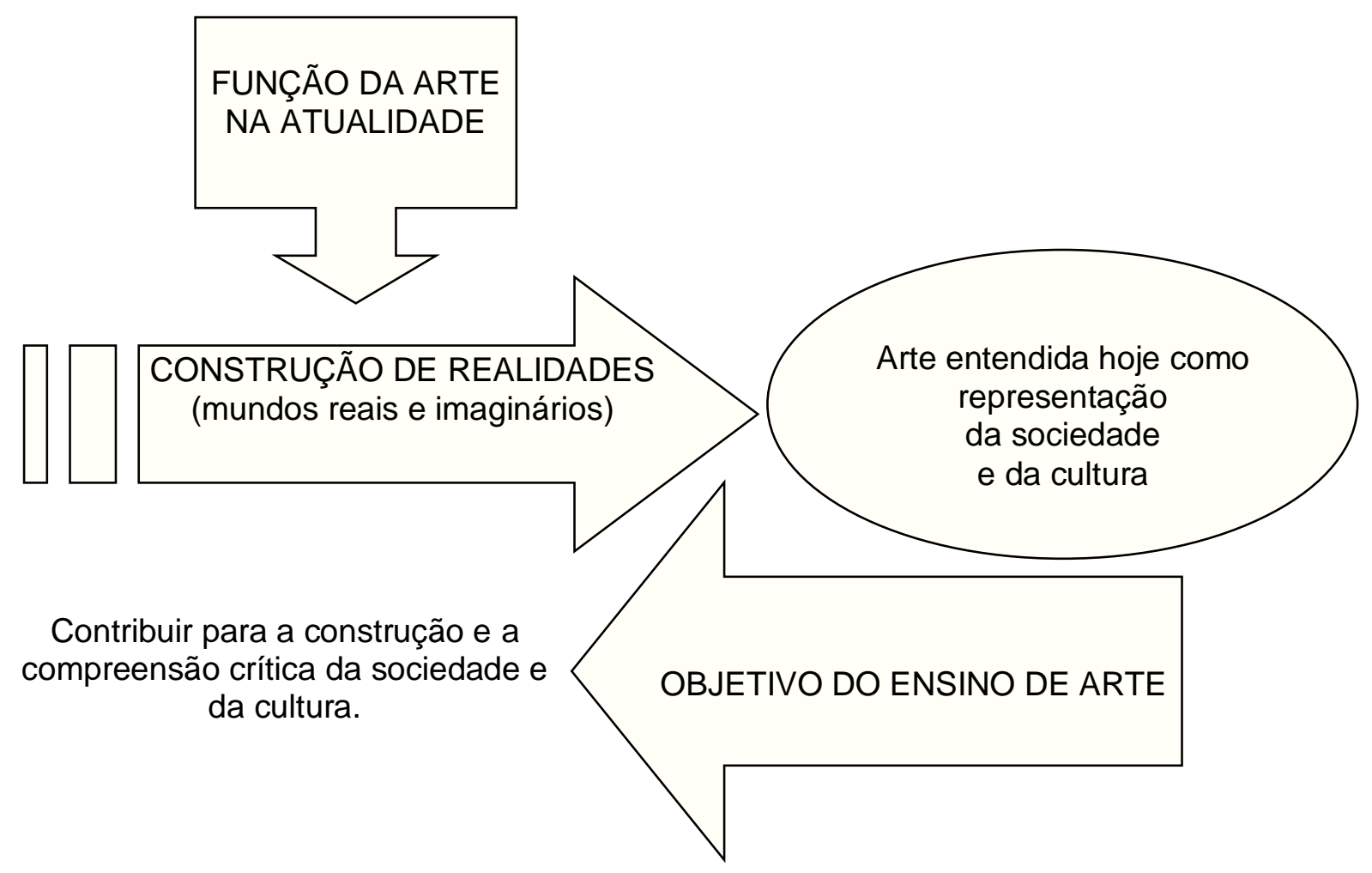

Para compreender obras artísticas como representações socioculturais (e não puramente estéticas), é necessário desenvolver complexos estudos, que exigem o domínio de diferentes âmbitos do conhecimento humano. Estes conhecimentos, segundo Franz (2003), podem ser de diversos campos interdisciplinares e DAPesquisa, Florianópolis, v.2, n.4, p. 303-310, 2007. 
transdisciplinares, tais como da História Cultural, da Antropologia, da Estética e da Pedagogia. A partir de abordagens socioculturais e contextualistas, e com base nas teorias críticas da arte e da cultura, através de uma pedagogia problematizadora e dialógica (FREIRE, 1987) nas abordagens pós-modernas de ensino de Artes Visuais, valorizamos também a relação que os indivíduos estabelecem entre a arte e sua vida pessoal e social. Por esse motivo ordenamos também, como vemos em Franz (2003), os âmbitos biográfico e crítico social na relação entre a compreensão das artes visuais e a educação. Desta maneira a aprendizagem faz sentido para os estudantes, "especialmente quando a conectam com os próprios interesses, experiências de mundo e vida" (Parsons, 2006, p.296). Ele também defende a idéia de que para obter significado e compreensão da arte são necessários conhecimentos de outras disciplinas, diz que um currículo integrado é mais adequado para ensinar e aprender determinados tipos de idéias com as quais nenhuma disciplina é capaz de lidar sozinha.

Para resolver o problema da complexidade da compreensão da arte, Fernando Hernández (2000) apresenta a proposta de ensino por projetos de trabalho, abordagem interdisciplinar e transdisciplinar da arte e da educação, que hoje se coloca entre as principais tendências pedagógicas contemporâneas da educação e do ensino da Arte.

Essas novas maneiras de abordar o ensino das Artes Visuais estão diretamente relacionadas às finalidades do ensino hoje. Nas tendências contemporâneas do ensino de Artes Visuais as finalidades da educação vão além do desenvolvimento da sensibilidade, da criatividade, da percepção estética, da fruição, da contemplação, da leitura formal. Nas tendências pedagógicas contemporâneas em Arte e Educação, as finalidades do ensino tornam-se mais amplas e complexas e mais alinhadas com os objetivos de toda a educação escolar em geral.

\section{Considerações finais}

A principal meta do ensino de Artes Visuais hoje é ajudar os estudantes que passam pela escola a entender criticamente a sociedade e a cultura. Arte/educadores contemporâneos, defendem também a idéia de que o ensino da Arte é um poderoso instrumento para resgatar a auto-estima, fortalece a identidade, ao mesmo tempo em que pode contribuir e propiciar a inclusão social e a educação DAPesquisa, Florianópolis, v.2, n.4, p. 303-310, 2007. 
para a cidadania e a democracia, o que inclui a preparação dos estudantes para as profissões relacionadas com as visualidades. Além da construção de mundos reais e imaginários e de educar para uma compreensão crítica da realidade, os meninos e meninas que freqüentam o ensino fundamental na sociedade contemporânea, podem sonhar com um mundo melhor. Onde podem se situar de modo mais inclusivo e competente, o que está resumido no esquema a seguir representado.

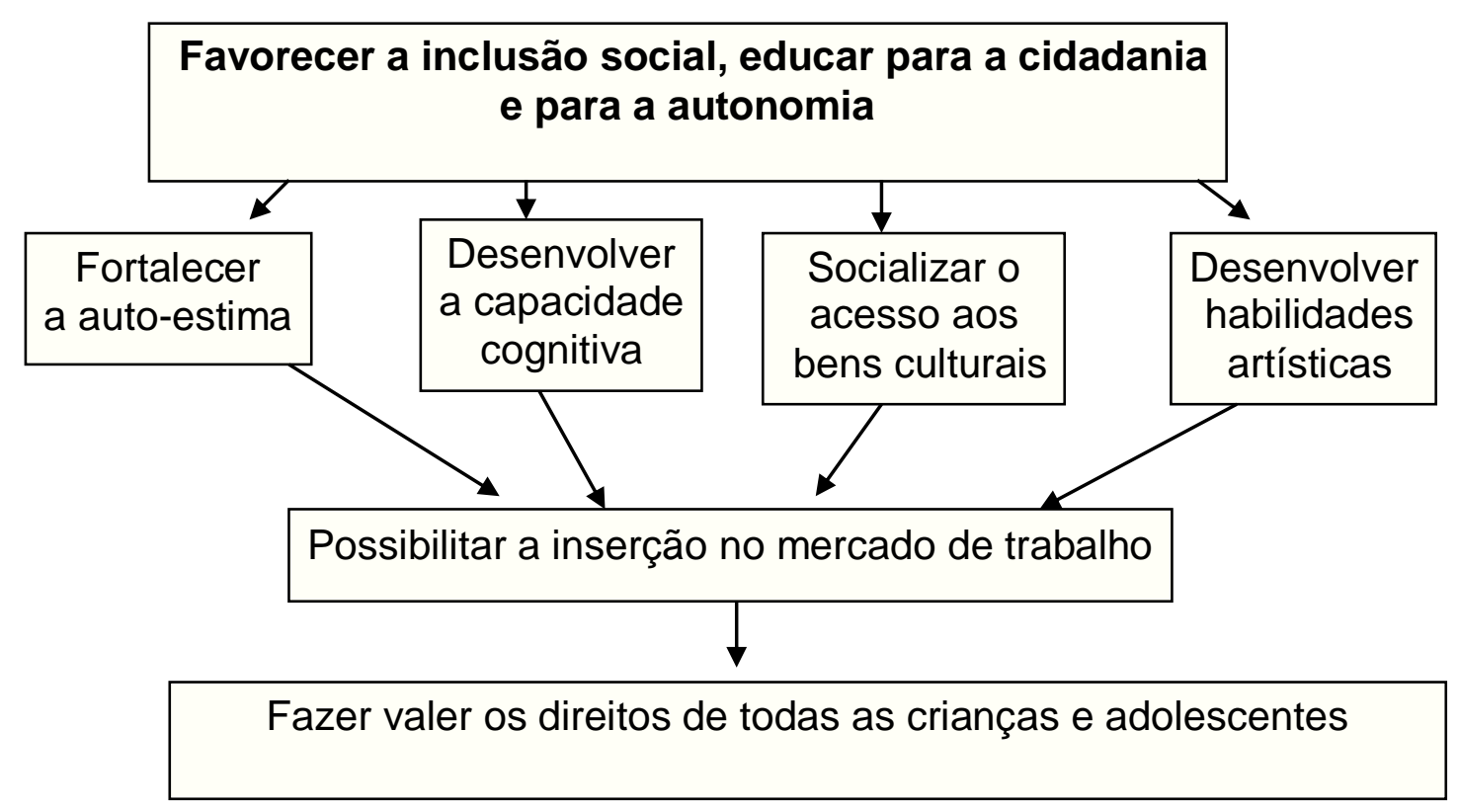

Além das questões acima colocadas, as tendências e finalidades das Artes Visuais no ensino fundamental na contemporaneidade apontam também para a necessidade de quebrar as barreiras que separam a arte erudita da cultura popular e das imagens do cotidiano. Kincheloe (1997) denuncia os antagonismos entre a cultura popular do aluno - que pode representar uma fonte de prazer pela convivência com elementos pertencentes ao seu imaginário social.

Segundo Carr (1996), a ciência crítica da educação propõe aos professores que construam suas práticas sociais voltadas à reflexão e à racionalidade, tendo uma posição articulada, pois a prática educativa é uma forma de poder, onde os professores podem exercer mudanças e por isso devem estar atentos às novas posturas contemporâneas da Teoria Social Crítica, que ajuda a encontrar os erros que foram cometidos ao longo da história da educação e fornece soluções possíveis para os problemas na educação em Arte.

DAPesquisa, Florianópolis, v.2, n.4, p. 303-310, 2007. 
Para entrar em sintonia com as tendências e finalidades do ensino de Artes Visuais contemporâneo, é necessário rever os marcos característicos da modernidade, que entende a arte como expressão subjetiva ou manifestação da essência individual (EFLAND, FREDMANN e STHUR, 2003, p.17). Se a finalidade principal da educação em Artes Visuais no ensino fundamental (ao lado das outras disciplinas do currículo escolar) é ensinar os estudantes a compreender criticamente o mundo que os rodeia, o universo de Artes Visuais também se amplia. A arte feita pelos artistas é apenas uma parte de nosso campo de estudos. O foco também vai para a cultura popular e a arte do cotidiano. As tendências pedagógicas atuais apontam para o estudo crítico do universo da Cultura Visual em geral. Ao se valer, por exemplo, de outras imagens e objetos da Cultura Visual, tais como quadrinhos, jogos eletrônicos, propagandas de TV, filmes, etc. os professores adentram o mundo simbólico e visual dos estudantes, se aproximando cada vez mais dos objetivos do ensino de Artes Visuais na contemporaneidade.

Por último, parece não haver dúvidas de que qualquer agenda para pensar as Artes Visuais no ensino fundamental (e outro contextos) para o século XXI há de ser baseada também em pedagogias que visem uma transformação pessoal e social.

\section{BIBLIOGRÁFIA}

JBARBOSA. A. M. A imagem no ensino da arte. São Paulo: Perspectiva, 1991.

BRASIL. Lei de Diretrizes e Bases da Educação Nacional no 9.394/96. Brasília: MEC, 1996.

Ministério da Educação. Secretaria de Educação Básica. Ensino Fundamental de Nove Anos: orientações gerais. Disponível em: <www.mec.gov.br>. Acesso em: nov 2005

. Parâmetros Curriculares Nacionais, v.6 - Arte. Brasília: MEC, 1997.

CARR, W. Una teoría para la educación: hacia una investigación educativa crítica. Madrid: Morata, 1996.

CARY, R. Critical art pedagogy. Foundations for Postmodern Art Education. New York and London: Garland, 1998.

DAPesquisa, Florianópolis, v.2, n.4, p. 303-310, 2007. 
CHALMERS, F.G. Arte, educación y diversidad cultural. Barcelona: Paidós, 2003.

DIAS, G. e FRANZ, T.S. Educação para uma compreensão crítica da arte no ensino fundamental. In: RELATÓRIO FINAL PROBIC/UDESC (Bolsista Gustavo Dias), apresentado ao DAP/CEART/UDESC, ago., 2004.

EFLAND, A.D.; FREEDMAN, K. e STUHR, P. La educación en el arte posmoderno. Barcelona: Paidós, 2003.

FRANZ, T.S. Educação para uma compreensão crítica da arte. Florianópolis: Letras Contemporâneas, 2003.

FREIRE, P. Pedagogia do oprimido. Rio de Janeiro: Paz e Terra, 1987.

FUSARI, M.F. e FERRAZ DE TOLEDO, M.H. Arte na educação escolar. São Paulo: Cortez, 1992.

GEERTZ, G. A arte como um sistema cultural. In: GEERTZ, G. O saber local Novos ensaios em antropologia interpretativa. Petrópolis: Vozes, 1999.

HERNÁNDEZ, F. Cultura visual, mudança educativa e projetos de trabalho. Porto Alegre: Artmed, 2000.

KINCHELOE, J.L. A formação do professor como compromisso político mapeando o pós-moderno. Porto Alegre: ArtMed. 1997.

PARSONS, M. Curriculum, arte e cognição integrados. In: BARBOSA. A. M. (Org.) arte/educação contemporânea - Consonâncias internacionais. São Paulo: Cortez, 2006. p.295-317.

RESENDE E FUSARI, M.F. e FERRAZ DE TOLEDO, M.H. Metodologia do ensino de arte. São Paulo: Cortez, 1993.

SANTA CATARINA. Governo de Estado. Proposta Curricular de Santa Catarina. Florianópolis: 1998. 